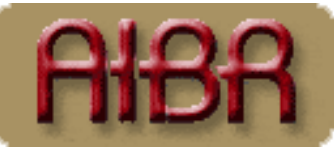

REVISTA DE ANTROPOLOGÍA IBEROAMERICANA

ESTIMADO LECTOR/A:

GRACIAS POR DESCARGAR ESTE ARTÍCULO. EL TEXTO QUE ESTÁ A PUNTO DE CONSULTAR ES DE ACCESO LIBRE Y GRATUITO GRACIAS AL TRABAJO Y LA COLABORACIÓN DESINTERESADA DE UN AMPLIO COLECTIVO DE PROFESIONALES.

USTED PUEDE AYUDARNOS A INCREMENTAR LA CALIDAD Y A MANTENER LA LIBRE DIFUSIÓN DE LOS CONTENIDOS DE ESTA REVISTA A TRAVÉS DE SU INSCRIPCIÓN A LA ASOCIACIÓN AIBR:

http://www.aibr.org/antropologia/aibr/socios.php

La asociación a AIBR tiene un coste mínimo al año, y le proporcionará las siguientes ventajas y privilegios:

1. Recibir en su domicilio la revista impresa, en Europa y América (tres números anuales), así como todas las novedades relativas al funcionamiento de la asociación.

2. Recibir en su domicilio, a precio especial o de forma gratuita, cuantas publicaciones adicionales edite la asociación.

3. Derecho a voto en las asambleas de socios, así como a presentarse como candidato a la elección de su Junta Directiva.

4. Recibir el boletín de socios (tres números anuales), así como la información económica relativa a cuentas anuales de la asociación.

5. Beneficiarse de las reducciones de precio en congresos, cursos, libros y todos aquellos convenios a los que a nivel corporativo AIBR llegue con otras entidades. En este momento, existen los siguientes acuerdos:

o Reducción de un $20 \%$ en el precio de todos los libros publicados por la editorial MELUSINA.

o Reducción de un $20 \%$ en el precio de todos los libros publicados por la editorial SEPHA.

o Reducción de un 30\% en el precio de todos los libros publicados por la editorial GRAN VÍA.

o Derecho a cuota reducida en los congresos trianuales de la FAAEE (España) y a los bianuales de la Sociedad Española de Antropología Aplicada.

o Derecho a cuota reducida en los congresos la IUAES.

6. Promoción gratuita, tanto a través de la revista electrónica como de la revista impresa, de aquellas publicaciones de las que sea autor y que estén registradas con ISBN. La difusión se realiza entre más de 5.000 antropólogos suscritos a la revista.

7. Cuenta de correo electrónico ilimitada de la forma socio@aibr.org, para consultar a través de webmail o cualquier programa externo.

8. Espacio para web personal de la forma http://www.aibr.org/(directorio)/(nombre) y cuenta propia de ftp.

9. Acceso con clave a todos los documentos de la Intranet de socios de AIBR, incluida la consulta a artículos en proceso de evaluación de la revista AIBR.

10. Promoción gratuita a través de la revista (banner rotativo y reseña) de aquellos eventos, congresos, conferencias o cursos en los que usted forme parte del comité organizador.

11. Opción a formar parte como evaluador de los artículos recibidos por la revista.

IMPORTE DE LA CUOTA ANUAL: Hasta diciembre de 2008, la cuota única anual es de 32 (euros). Su validez es de un año a partir del pago de la cuota. Por favor, revise la actualización de cuotas en nuestra web. 


\title{
PदR CODESARROLLO: LA OPCIÓN INSTITUCIONAL PARA EL VÍNCULO MIGRACIÓN Y DESARROLLO
}

\section{Cristina Gómez Johnson}

Universidad Complutense de Madrid, Facultad Historia y Geografía. Centro Universitario Ortega y Gasset. Investigadora del Ministerio de Educación y Ciencia. E-mail: crisismilenio@yahoo.com.mx

\begin{abstract}
Resumen
El presente artículo busca realizar un breve recorrido por la experiencia de codesarrollo en Europa, en especial en España. Se centra en las iniciativas gubernamentales que se han ido desarrollado desde fines de los 1990 con la llegada masiva de migrantes a la región, y la evolución de las mismas. El codesarrollo es la política en la que se centra el artículo, empezando por su surgimiento en Francia hasta llegar a España, desde el gobierno central hasta algunas comunidades autónomas. Para hacer visible esta evolución y su efectividad, se menciona el caso mexicano, cuya experiencia demuestra que el vínculo entre la migración y el desarrollo es posible, aunque únicamente si las iniciativas surgen de los propios migrantes y sus comunidades.
\end{abstract}

\section{Palabras claves}

Codesarrollo, comunidades transnacionales, cooperación al desarrollo.

\begin{abstract}
This paper is an attempt to present the experience of co-development in Europe and particularly in Spain. It is focus on the governmental initiatives since the end of the 1990's decade, as a consequence of a massive reception of migrants. Co-development is the policy in which this paper is focused, from its former periods in France to the moment in which it has been considered in Spain. In order to show this evolution and its effectiveness I use the Mexican case, because it demonstrates that there is a feasible link between migration and development. However, this it is only possible if the initiatives are coming from the migrants and their communities.
\end{abstract}

Keywords

Co-development, transnational communities, cooperation, development

Recibido: 13 de Junio de 2007

AIBR. Revista de Antropología Iberoamericana. www.aibr.org

Volumen 2, Número 3. Septiembre-Diciembre 2007. Pp. 550-569

Madrid: Antropólogos Iberoamericanos en Red. ISSN: 1695-9752 
Aceptado: 29 de Agosto de 2007

\section{Introducción}

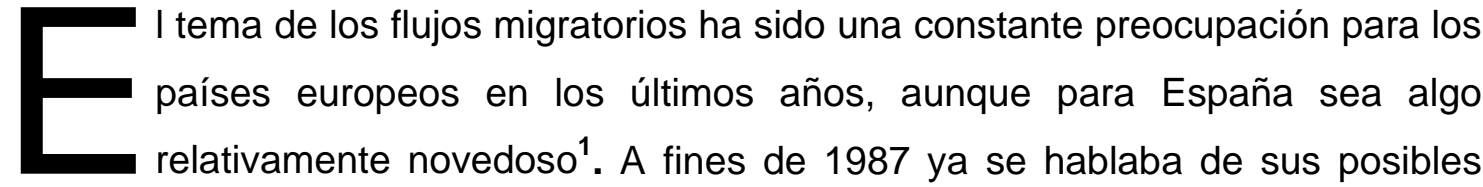

repercusiones y las maneras de enfrentarlos.

En los próximos años las migraciones seguirán ejerciendo presión sobre los países desarrollados. Será una presión intensa con grandes probabilidades de acentuarse y, en cierto modo, imposible de evitar. El problema más importante y el más difícil de resolver es el relativo a la acción en pro del desarrollo económico, por tanto, del aumento del empleo en los países de origen. La puesta en marcha de una cooperación más intensa, más productiva y más eficaz entre el Norte y el Sur parece la única salida (OCDE, El porvenir de las migraciones, París: 1987).

La Unión Europea se manifestó hacia 1993 por una cooperación basada en un sentimiento de responsabilidad común y solidaria entre los países de origen y de destino de los flujos migratorios, con el fin de adecuarlos y conducirlos bajo propósitos determinantes de los países receptores. Pareciera que estamos nuevamente ante una cooperación vertical cuyo interés es frenar los flujos migratorios, sin tomar en cuenta todas las razones que ocasionan estos y si verdaderamente una cooperación más "solidaria" podría frenarlos. La pregunta que quizá nos debemos hacer es si el desarrollo realmente frenaría los flujos migratorios. La experiencia nos dice que no, al menos en algunos $\operatorname{casos}^{2}$, pero dicho cuestionamiento supera las pretensiones de este trabajo.

\footnotetext{
${ }^{1}$ No podemos olvidar que España hasta hace una treintena de años era un país de emigrantes incluso ahora se encuentra entre los 10 primeros países que reciben la mayor cantidad de remesas en el mundo-. La inmigración se ha convertido en un problema que no se tiene claro cómo resolver. Las leyes españolas no contemplaban hasta 1985 una Ley de Extranjería, que por ese entonces se quedó corta para gestionar los flujos migratorios. Ahora se ha adoptado una política restrictiva, que no busca la gestión sino el control de los flujos migratorios.

2 Tratar la migración solo en base a cuestiones económicas sería limitado, pues muchas veces se toma la decisión de migrar en busca de mejores oportunidades profesionales o por cuestiones de seguridad. De esta manera, hay países que a pesar de la ayuda que reciben no han logrado salir de las crisis económicas y sociales que los embaten. El caso de Marruecos es representativo, pues a pesar de ser un país con el cual España tiene una relación estrecha de cooperación, esto no ha evitado que sus habitantes intenten atravesar el estrecho en busca de trabajo.
} 


\section{Antecedentes del codesarrollo: Francia}

Partamos primero de ciertas definiciones. En 1985 se firmó en Schengen (Luxemburgo) un acuerdo entre algunos países de Europa (Francia, Alemania, Reino Unido, entre otros) para suprimir las fronteras interiores y aumentar el control de las exteriores. En consonancia con dicho acuerdo se acordaron políticas comunes con respecto a visados, asilo y cooperación judicial que permitieran enfrentar la "nueva" situación -sin fronteras- en temas como migración, asilo y fronteras exteriores, en el marco del conocido acuerdo de Maastricht de 1983. A éste le siguieron otros ${ }^{3}$ con miras a gestionar de la mejor manera posible la migración (legal e ilegal), asilo y otros problemas que la joven Unión Europea enfrentaba. La Cumbre de Tampere (1999) creó lo que se conoce, de manera bastante sonora, como "el Espacio de Libertad, Seguridad y Justicia"4 . El texto redactado empieza recordando los principios sobre los cuales se fundamenta la Unión Europea y su objetivo primario: la libertad. Ésta incluye el derecho a circular libremente por todo su territorio, en condiciones de seguridad y de justicia accesibles a todo el mundo. ¿Quién es "todo el mundo", en este caso? El texto deja claro que son todos los residentes en la Unión Europea. Añade que "por esta razón, la Unión ha de desarrollar políticas comunes en materia de asilo y de inmigración, teniendo en cuenta al mismo tiempo la necesidad de llevar a cabo un control coherente de las fronteras exteriores para poner fin a la inmigración ilegal y para luchar contra

\footnotetext{
3 Tratado de Dublín: El 15 de junio de 1990 se firmó en Dublín un Convenio relativo a la determinación del Estado responsable del examen de las solicitudes de asilo presentadas en los Estados miembros de las Comunidades Europeas. Dicho Convenio entró en vigor el 1 de septiembre de 1997. Con posterioridad, el Comité creado en virtud del mismo adoptó distintas medidas de aplicación, entre ellas Eurodac, una base de datos destinada a recoger las huellas dactilares de los solicitantes de asilo y de los inmigrantes ilegales.

Plan de acción de Viena: El plan de acción del Consejo y la Comisión sobre la mejor manera de aplicar las disposiciones del Tratado de Amsterdam relativas a la creación de un espacio de libertad, seguridad y justicia, estableció una lista concreta de los objetivos que deben alcanzarse a medio plazo (dos años) y a más largo plazo (cinco años), y la lista de las medidas a adoptar. Las principales medidas previstas fueron la creación de un espacio judicial europeo, la mejora de la cooperación entre las Administraciones nacionales judiciales y policiales, el refuerzo de Europol y la definición de una estrategia global relativa a los fenómenos migratorios y la política de asilo y de acogida de los refugiados.

${ }^{4}$ El Consejo Europeo de Tampere reunido en octubre de 1999 definió en sus conclusiones las 4 grandes líneas de la política migratoria común: colaboración con los países de origen, establecimiento de un sistema europeo común de asilo, trato justo a los nacionales de terceros países y gestión de flujos migratorios.
} 
quienes la organizan y cometen delitos internacionales conexos" (Terrón, 2001). Acaba reconociendo que los principios sobre los que deben basarse estas políticas tienen que ser claros para los propios ciudadanos y, además, han de ofrecer garantías a las personas que busquen protección en la Unión Europea o intentan ingresar en ella. Su primer elemento, la colaboración con los países de origen, se refiere a un enfoque global de la migración que tenga en cuenta la situación económica y social en aquellos países. En este sentido, pide coherencia entre las políticas exteriores e interiores de la Unión. En su origen, esta propuesta pretende incorporar la idea de codesarrollo y gestión común de los flujos migratorios, aunque finalmente no haya habido progreso a este respecto ${ }^{5}$.

En el tema puntual de codesarrollo fue Francia la pionera, tras la llegada de Sami Naïr al gobierno francés como secretario interministerial de Codesarrollo y Migraciones Internacionales (1997-1999): “ [se trata] de una propuesta para integrar inmigración y desarrollo de forma que ambos países, el de origen y el de destino, puedan beneficiarse de los flujos migratorios. Es decir, es una forma de relación consensuada entre dos países de forma que el aporte de los inmigrantes al país de destino no se traduzca en una pérdida para el país de origen" (Naïr, 1997). En esta definición es interesante resaltar la idea de la integración de la inmigración y el desarrollo por un lado, y su posible relación consensuada entre países de origen y destino, por otro. Para ello es necesario eliminar la connotación negativa sobre el impacto de las migraciones en los países de destino, además de superar la idea de que la migración es debida exclusivamente al subdesarrollo de la región de origen, y que los países receptores podrían tener un desarrollo igual o mejor sin la inmigración. No se trata de afirmar que los factores económicos no tengan un peso fuerte en la decisión de emigrar, pero sí que los beneficios de la misma son usufructuados, en buena medida, por los países de destino. La búsqueda del beneficio mutuo sería un factor definitorio para el codesarrollo.

\footnotetext{
${ }^{5}$ A casi siete años de Tampere, la política migratoria europea se ha caracterizado por endurecer las "reglas del juego" para así evitar la entrada -ilegal- de inmigrantes, sin importar si éstos son asilados o trabajadores. Incluso se han creado campos de refugiados fuera de territorio europeo, intentando limitar el flujo de migrantes. Se ha dejado de lado la integración intercultural entre migrantes y autóctonos. La muestra es que durante las presidencias europeas a partir de 2000 no ha habido programas que fomenten la integración de los inmigrantes, pero sí propuestas destinadas al control y el combate de la inmigración irregular, relacionándola muchas veces con delincuencia. Nuevamente la prioridad es el control y el combate. Los países miembros de la UE han adoptado esta misma actitud.
} 
Naïr defendía/proponía el codesarrollo como la posibilidad de "ir más allá" de la cooperación tradicional, mediante objetivos comunes entre el país de destino y el país de origen de la migración para gestionar los flujos migratorios en origen y facilitar la integración en la sociedad receptora.

La política de gestión de flujos migratorios debe favorecer la estabilización de los inmigrantes legalmente instalados, su integración social, el control de la entrada en el país, y el respeto de las reglas de residencia. Se articula también sobre la política exterior del país. Si la inmigración constituye un aporte real a partir del momento que corresponde a las necesidades del país, no por ello debe ser una falta de ganancias para los países de origen (Naïr, 1997).

En el documento titulado "Rapport de bilan et d'orientation sur la politique de codeveloppement lieé aux flux migratoires" (1997), realizado por Sami Naïr, se pueden destacar siete lineamientos principales: el primero está dirigido a una gestión de flujos migratorios en busca de beneficios tanto para los sociedades de origen como para las de destino. Para ello se busca una integración satisfactoria de las poblaciones legalmente instaladas en los países de destino (en su caso Francia). Segundo: buscar acuerdos entre ambos gobiernos (origen y destino) para la mejor aplicación de políticas de codesarrollo. Con ello se busca evitar las "cuotas" de trabajadores que normalmente apuntan a acoger las categorías que mejor convengan a las necesidades del país de destino. Con el codesarrollo se busca tener "contingentes" de personas destinadas a formarse en los países de destino, en vista del retorno programado al país de origen. Tercero: formar a los migrantes como agentes de desarrollo, sin importar si vuelven o no a sus países de origen. Sin embargo, se pretende organizar los nuevos flujos de manera que no se favorezca su instalación definitiva en el país de destino, sino su reinstalación en su país de origen. Cuarto: fortalecer las redes y asociaciones de migrantes para facilitar su integración, así como para continuar con un vínculo con las sociedades de origen. Quinto: buscar que tanto el Estado como los gobiernos locales, sociedad civil y empresa privada se vinculen con los proyectos de codesarrollo. Sexto: involucrar a los migrantes tanto en la concepción, como en la aplicación de proyectos de desarrollo, para que éstos sean lo más adecuados a la realidad de las sociedades de origen. Finalmente, incentivar puentes de comunicación, formación e interacción entre migrantes y sus comunidades. La proposición de Naïr constituyó en ese momento una propuesta política gubernamental, no sólo a nivel local, sino de toda Europa. 
Una de las cuestiones novedosas es que la migración se presenta como un instrumento económico de la cooperación al desarrollo, convirtiendo al inmigrante en un actor consciente, actuante y central del mismo. Lo que se busca es que los inmigrantes se conviertan en "agentes transnacionales" para el desarrollo. Para ello es necesaria una sistematización de sus experiencias migratorias de cambio individual y social; la potenciación individual en el marco de organizaciones sociales de base, y la concienciación sobre los beneficios que genera la doble pertenencia a la sociedad de origen y a la de vinculación.

Los proyectos de cooperación y los de codesarrollo comparten el hecho de ser líneas de impulso del desarrollo humano basados en la solidaridad, pero se diferencian en el carácter horizontal de las relaciones de los segundos frente a la verticalidad de los primeros (donantereceptor / norte-sur). El codesarrollo busca el desarrollo simultáneo y conjunto de ambas sociedades. Así, incluye a la sociedad receptora en el sentido de enriquecimiento recíproco. De este modo, los objetivos se formularían atendiendo a los intereses mutuos, desde una perspectiva intercultural y no jerárquica (Zúñiga, 2005: 103-104).

Sin embargo, entre los intereses de la sociedad de destino continúa primando el control y la gestión de flujos migratorios. "El control de flujos de inmigración [hacia] la Unión Europea y a otros países de la OCDE sigue siendo una cuestión de máxima prioridad para las autoridades migratorias, de igual manera que la integración de los inmigrantes en el mercado laboral y en la sociedad en general" (Ibid., 2005: 106). Con esta prioridad siempre presente, ¿cómo se puede establecer una colaboración con los países en desarrollo? En este sentido, es importante destacar que no es responsabilidad de los inmigrantes, sino del Estado, la generación de desarrollo económico en sus países de origen. Sin embargo, si la vinculación va a ser efectiva, es necesario determinar las razones de la migración, los impactos económicos, sociales y culturales de la migración tanto en los países de origen como en los de destino; la relación que se puede establecer con la cooperación al desarrollo y quizá hacer una propuesta de intercambio entre ellas ${ }^{6}$.

\footnotetext{
${ }^{6}$ Primero se tendría que establecer la diferencia entre control y gestión de los flujos migratorios. EI control de flujos migratorios tiene como misión principal evitar la entrada de migrantes irregulares a los países del norte. Siendo además labor de los ministerios de cada país, así como de la propia UE. Sin embargo, la gestión de los flujos tiene una carga no tan coercitiva. El que habla de gestión entiende que el control no ha sido suficiente y es necesaria una tarea de colaboración entre los países de emisión, tránsito y admisión. Y finalmente aprovechar los flujos por parte de los tres países inmiscuidos. Sin embargo, y esto hay que mencionarlo, el fin último de la gestión -aunque de manera menos agresiva- es manejar y controlar los flujos migratorios. El codesarrollo no se plantea para el control restrictivo de los flujos migratorios, sino para una gestión positiva de los mismos.
} 


\section{El codesarrollo en España}

Durante el gobierno de José María Aznar (PP), se creó el Plan GRECO (Programa Global de Regulación y Coordinación de la Inmigración y Extranjería en España, 2001), el cual se centraría en frenar los flujos migratorios e intentaría coordinar las masas de migrantes que ya estaban en España ${ }^{7}$. El Plan está divido en cuatro líneas básicas de actuación, siendo la última la que establecía una estrategia de acción sobre el codesarrollo en cinco tipos de actividades (siempre con la constante intención de frenar la llegada de migrantes y favorecer el retorno de los que ya están en España): formación de los inmigrantes para que puedan ser agentes de desarrollo a su regreso a su país de origen (Ministerio de Asuntos Sociales); ayuda a la reinserción de los inmigrantes en sus países de origen (Ministerio de Asuntos Sociales); ordenación del ahorro hacia inversiones productivas en los países de origen (Ministerio del Interior); concesión de microcréditos en los países de origen para financiar actividades productivas (Ministerio de Asuntos Sociales), y asistencia técnica en las zonas de donde proceden los inmigrantes (AECI). La mayor crítica que ha recibido este proyecto es su centralismo. Se mantiene ajeno a la sociedad civil y a los propios migrantes. El papel de la sociedad civil y el rol de los ayuntamientos no están contemplados, los proyectos están planteados para realizarse desde el gobierno central, la responsabilidad recae en los ministerios de Interior y de Asuntos Sociales. En ningún momento se hace mención a la participación ni de los gobiernos de las comunidades autónomas ni mucho menos de los ayuntamientos. Sin embargo, la voluntad política de tratar el codesarrollo tampoco se ha traducido en una previsión presupuestaria específica. Se plantea así una estrategia para los migrantes, pero sin ellos, pasando por alto que en los países de destino [de la cooperación] también existen planes de desarrollo alternativo. Además esta actitud va en detrimento de la sociedad de destino, pues el plan está diseñado sólo en una dirección, cayendo nuevamente en

\footnotetext{
${ }^{7}$ Durante los dos periodos del gobierno de Aznar las cuestiones migratorias estuvieron a cargo del Ministerio del Interior. Así marcó su política migratoria, vinculada a un ministerio que se encarga de la seguridad nacional. No es de extrañar que durante su último periodo se vulneraran los derechos sociales de los migrantes, quitándoles -entre otros- el derecho a un abogado de oficio, a servicios de la seguridad social y educación básica. EI PSOE dejó nuevamente en manos del Ministerio de Trabajo y Asuntos Sociales las cuestiones migratorias.
} 
una cooperación al desarrollo tradicional ${ }^{8}$. Se plantea así que además de crear un marco legislativo que articule el trabajo de los inmigrantes y el desarrollo de sus comunidades de origen" (Terrón, 2004: 16-18), éste vaya acompañado de unas condiciones específicas para la integración de los inmigrantes en este proceso. Por ejemplo un acercamiento efectivo a los colectivos con mayor presencia en el país, para conocer cuál es su proyecto migratorio y en qué estado se encuentra.

En el ámbito autonómico, el abordaje del tema es desigual. En el caso de Cataluña hay una previsión para proyectos de desarrollo en las comunidades de origen de sus inmigrantes. No sucede lo mismo en Extremadura, en cuyo plan director de cooperación al desarrollo no se contempla el codesarrollo. En cambio, Castilla la Mancha y Baleares sí lo hacen. La Comunidad Valenciana no tiene un marco normativo de la cooperación al desarrollo con rango de ley, pero sí cuenta con un borrador de Plan Director que hace mención al codesarrollo como un concepto que vincula la inmigración con el desarrollo. El País Vasco ya contempla un proyecto de investigación que aglutina diferentes estrategias de colaboración para valorar la idoneidad de incorporar el mecanismo del codesarrollo en la política de cooperación vasca. Como resultado de esta investigación resultaron tres proyectos de codesarrollo en dicha comunidad. El codesarrollo también está contemplado en el Plan de Inmigración del País Vasco 2003-2005. En Madrid la línea de codesarrollo comienza a estar presente en el Plan de Desarrollo sólo hasta 2004, antes no se hacía mención a una iniciativa distinta a la cooperación al desarrollo ${ }^{9}$. Por otro lado, no se hace mención del vínculo entre cooperación al desarrollo y migración en las siguientes comunidades: Andalucía, Aragón, Galicia, La Rioja, y Navarra. (Terrón, 2004: 18-22). Asimismo, es interesante observar que a

\footnotetext{
${ }^{8}$ Opiniones recogidas en las Jornadas sobre Codesarrollo e Inmigración (25 y 26 de septiembre de 2003), en las que participaron tanto miembros de la comunidad académica como del gobierno del entonces presidente Aznar.

${ }^{9}$ En 2004, el Ayuntamiento de Madrid regularizó la nueva línea de trabajo de apoyo a Proyectos de Codesarrollo, en la Ordenanza Reguladora de las Bases de Subvenciones Generales, que se aprobó en el Pleno del 20 de febrero de 2004. Tal y como dispone en su Titulo VI, articulo 11, cada año se convocarán las distintas Convocatorias Públicas, entre las que se encuentra la Convocatoria de Ayudas a Proyectos de Codesarrollo. La convocatoria general de Cooperación no tenía en cuenta, suficientemente, determinados aspectos técnicos distintivos que llevan consigo los proyectos de codesarrollo, en cuanto a objetivos, protagonistas, recursos humanos, localización de actividades o justificación de gastos. Fue por eso que se hizo una convocatoria específica para Codesarrollo. En este sentido la Convocatoria de subvenciones a Proyectos de Codesarrollo es distinta, pero complementaria, tanto de la convocatoria general de Cooperación para el Desarrollo como de las convocatorias referidas a la integración de los inmigrantes (Ayuntamiento de Madrid 2006).
} 
nivel estatal existen pocas iniciativas para gestionar proyectos de codesarrollo ${ }^{10}$. Mientras que algunas comunidades autónomas se están movilizando de manera más activa en la propuesta de proyectos que vinculen a los inmigrantes con sus regiones de origen y a su vez con España. Esto no es raro, pues en última instancia son los gobiernos regionales quienes cotidianamente lidian con los flujos migratorios. Finalmente podemos observar que los proyectos de codesarrollo no se están construyendo en el ámbito nacional, y más aún que ni siquiera se están concentrando en un nivel gubernamental. El codesarrollo se podría ubicar en el ámbito de cooperación descentralizada -que es donde se sitúan la mayoría de las experiencias que se están iniciando en España-, las encargadas de llevar a cabo los proyectos son ONG tanto de los países de origen como de destino. Sin embargo, hay que destacar la necesidad de un correcto engranaje entre distintos ámbitos para el buen desarrollo de estos proyectos; además de la participación activa de los migrantes.

A pesar de que el debate sobre la migración ha tomado mucha fuerza, aún no se incluye en él a los inmigrantes, siendo el codesarrollo la forma de subsanar esta situación, aunque de momento no lo logra. Por un lado, se pretende generar mayor desarrollo en los países de origen, partiendo del supuesto que a mayor desarrollo más posibilidades laborales y sociales y, por tanto, menor necesidad de salir a otros países en busca de oportunidades. De esta manera, la migración se convertirá en una opción y dejará de ser una necesidad. Este es el punto primordial de los programas de codesarrollo, frenar los flujos migratorios. Los gobiernos en Europa, particularmente en España, han sido sobrepasados por el fenómeno migratorio y al no encontrar unas políticas públicas adecuadas para hacerle frente, han decidido unir fuerzas y luchar contra él. En este contexto surge el codesarrollo, planteando programas de desarrollo que subsanen las necesidades socioeconómicas en los países emisores de migrantes, pero sin tomar en cuenta las razones por las que los migrantes salen de ellos. Aunado a esto, buscan hacer responsables a los migrantes

\footnotetext{
${ }^{10}$ Existen algunos acuerdos firmados de manera particular entre el gobierno español y algunos países emisores de migrantes -como es el caso de Ecuador o Colombia, con el fin tener una gestión clara y ordenada de los flujos que vienen de esos países. Sin embargo, ninguno de estos acuerdos ha favorecido un desplazamiento fluido de personas. Pareciera que se han endurecido las políticas migratorias. El problema quizá radique en la poca comunicación entre ministerios, que no permite un engranaje entre las políticas migratorias y las de cooperación. Finalmente con los proyectos de codesarrollo no se busca frenar los flujos migratorios, sino aprovecharlos en beneficio de ambos países.
} 
del desarrollo de sus países, cuando es labor de los gobiernos garantizar servicios sociales e infraestructura económica básica. Lo que pretende el codesarrollo es generar proyectos con la estrecha vinculación de los posibles beneficiados, buscando adecuarlos más a sus necesidades y proyectos, y consiguiendo así ser exitosos a la luz de sus intereses. Sin embargo, para garantizar la viabilidad de dichos proyectos, es necesario que los migrantes participen no sólo en su aplicación, sino también en su concepción y elaboración. Un ejemplo fructífero de este vínculo entre migración y desarrollo es el caso mexicano.

\section{Comunidades transnacionales mexicanas en Estados Unidos}

El transnacionalismo en las migraciones se ha considerado, por algunos autores, como una resistencia desde abajo; una manera de escapar al control tanto del capital como del Estado. "La hibridación cultural, las identidades multiposicionales, el cruce de fronteras por 'otros' marginales y las prácticas comerciales transnacionales de los empresarios migrantes se plantean como esfuerzos conscientes y exitosos de las personas ordinarias por escapar del control y la dominación 'desde arriba' del capital y del Estado” (Guarnizo y Smith, 1999: 88) Asimismo, la constitución de comunidades transnacionales es la respuesta a la dificultad que enfrentan los migrantes para su inserción social en las comunidades de destino. También se reconoce el carácter emancipador del transnacionalismo, en la idea que defienden Guarnizo y Smith, como contestatarias del orden estatal. Estas prácticas están determinadas por las relaciones que se establecen entre una y otra sociedad, así como por las características sociales, económicas y culturales de los migrantes.

En este proceso encontramos a dos actores importantes. Por un lado, el Estado, que en los últimos años ha promocionado actividades transnacionales en beneficio de la comunidad de origen, pues de esta manera logra mantener los lazos socioeconómicos con sus nacionales fuera del país. "La gama de respuestas estatales en los países de origen puede ser muy variada. Entre ellas encontramos: cambios en la legislación para permitir la doble nacionalidad, políticas para facilitar la participación política de los migrantes, fomento del envío de remesas y de la cooperación con el país de origen, promoción de asociaciones y organizaciones de 
origen, etc." (Moraes, 2004: 3). Por otro lado, se encuentran los migrantes que forman asociaciones en busca de una mayor participación en el desarrollo sociopolítico, tanto de sus comunidades de origen como de las de destino. En las comunidades de destino demandan la homogeneización de los derechos sociales de los migrantes frente a los nacionales. Mientras que en las de origen, buscan una presencia más fuerte en decisiones políticas y sociales. La prioridad que se da a una lucha y otra depende de su proyecto migratorio. En tanto su meta sea la integración en destino, darán mayor importancia a las conquistas por mejorar condiciones de integración social, cultural y jurídica. En cambio, si su intención es regresar a sus países, entonces buscarán involucrarse de manera activa en los procesos sociopolíticos en origen.

Finalmente, un factor que no hay que olvidar en la formación de asociaciones es la necesidad de pertenencia que tienen los migrantes cuando se encuentran fuera del país. Esto puede ser generado por una sociedad hostil que los margina, o por la necesidad de mantener las tradiciones y costumbres que se pretenden ir transmitiendo a las generaciones siguientes.

Las asociaciones son un ámbito de socialización a través del cual se pueden suplir esas redes sociales que tanto cuestan construir en el nuevo país, son un medio que permite la vinculación social con personas del mismo origen, proporcionando un sentimiento de continuidad y de pertenencia comunitaria. Estas nuevas redes sociales generadas a partir de la migración ayudan a los migrantes a redefinir su propia identidad y el sentido de pertenencia. Se convierten así en un capital para afrontar la situación de vulnerabilidad social, ya no sólo porque en algunos casos les proporcionan ayuda económica y contactos laborales sino porque les otorgan el sentido de pertenencia perdido al migrar, indispensable según algunos de ellos, para poder reanudar su vida e integrarse en sociedad (Moraes, 2004: 11).

En este sentido, se ha generado la duda sobre si las prácticas transnacionales durarán más allá de la primera generación. Hay consenso en que esto depende de los modos de integración asumidos por la sociedad de destino.

[...] las distintas prácticas de los Estados receptores (por ejemplo, el pluralismo étnico en los Estados Unidos comparado con la asimilación total en Francia) siguen inclinando la balanza a favor de la asimilación con el tiempo, ya que la renovada histeria anti-inmigrante crea mayores presiones para que los 'inmigrantes' se asimilen o 'regresen a casa' en lugar de mantener la doble conciencia que se requiere de los transmigrantes (Guarnizo y Smith, 1999: 98).

Para ejemplificar este proceso tomamos el caso mexicano, pues cuenta con una de las migraciones más antiguas hacia Estados Unidos. El avance que han 
logrado los migrantes para optimizar las redes transnacionales en pro del desarrollo ha sido digno de estudio. Asimismo, el papel que ha jugado el Estado ha acelerado en algunos casos el proceso, aunque en otros entorpeció la realización de algunos proyectos. El interés mostrado por el Estado mexicano hacia las comunidades transnacionales obedece a razones de diversa índole: desde las que buscan aprovechar el mercado potencial que representan los mexicanos en Estados Unidos para las exportaciones de productos mexicanos, pasando por la dependencia que se tiene de las remesas, hasta buscar robustecer al Estado en pro de la defensa de los derechos humanos de sus nacionales en el extranjero. Sin olvidar también que la presencia de comunidades mexicanas en Estados Unidos genera una influencia importante en su política interna y externa.

\section{Estado mexicano y sus comunidades transnacionales.}

Las actividades transnacionales son los intercambios transfronterizos realizados por los migrantes con sus comunidades de origen, sin importar el tiempo que han permanecido fuera del país. La relación entre Estado y transmigrantes cobra importancia por la creciente politización de los espacios transnacionales y por la participación de actores dentro de estos espacios (Goldring, 1999). Sin embargo, las primeras organizaciones migrantes mexicanas establecidas en Estados Unidos eran pequeñas asociaciones de ayuda para enfrentar situaciones de enfermedad o de deceso de algún miembro de la comunidad, ya sea para el entierro o el traslado del cuerpo. El comité más antiguo era la Beneficencia Mexicana (1930), que es el antecesor de la Federación de Asociaciones Zacatecanas. Asimismo, se constituyeron los clubes de oriundos, como una forma de mantener la identidad de localidades mexicanas que sufren un alto índice de migración. Primeramente se forman alrededor de clubes de fútbol o comités religiosos, para luego dar paso a proyectos colectivos de desarrollo a favor de sus comunidades de origen: lucha por derechos humanos $\mathrm{u}$ otros. "Recientemente, los clubes de oriundos han incursionado en la vida política de sus comunidades de origen y destino [...] Al igual que otras organizaciones de autoayuda, formadas por diferentes grupos de inmigrantes en el siglo $\mathrm{XX}$, estas asociaciones funcionan como redes sociales y 
como transmisores de la cultura y los valores mexicanos a la segunda generación de inmigrantes" (Bada: 2004, 82-83).

En inicio no parecían tener demasiado interés por lo que sucedía en origen, aunque esto ha ido cambiando, pues se han dado cuenta que al participar activamente en la vida política de México también pueden influir en el destino de sus comunidades y mejorar las condiciones de la familia que todavía queda allí. Con el envío de las remesas ellos son todavía contribuyentes en México, y por esta razón desean influir en las decisiones sobre cómo se usan estas transferencias. Están preocupados por las escuelas públicas, los parques, la salud, etc. Pero además de esto, desean volverse visibles, es decir, ganar espacios en donde su voz sea escuchada, como una manera de recuperar su identidad y sobretodo su posición en la sociedad de origen. El deseo de participación política, con el derecho al voto en el extranjero por ejemplo, es un paso más en la recuperación de sus derechos. De cualquier manera, la vía electoral no ha sido, hasta ahora, la única manera de tener contacto e influencia en sus comunidades de origen. Han participado en "[...] actividades cívicas, tales como el mejoramiento del nivel de vida de sus coterráneos a través del financiamiento de proyectos de embellecimiento comunitario e infraestructura básica para sus pueblos" (Ibid. 84). La labor principal de estos clubes es el desarrollo económico de sus localidades de origen, aunque no mediante proyectos productivos que generen empleo, sino con inversiones para el desarrollo de infraestructura.

Con esta experiencia inicial, los grupos de mexicanos en Estados Unidos han ido absorbiendo, con el tiempo, otro tipo de actividades en sus comunidades de origen, tales como la construcción de escuelas, salones sociales, clínicas, centros deportivos, pavimentación de calles, pozos, etc. Algunas asociaciones también se han enfocado a la ayuda legal, así como la generación de programas culturales en Estados Unidos. Otras han desarrollado lazos con políticos locales, gobiernos y con organizaciones comunitarias de Estados Unidos y México. A pesar de esto, no se han identificado con las organizaciones étnicas, que rescatan derechos y necesidades de los "latinos", y por tanto están más interesadas en cuestiones políticas y derechos civiles, buscando el empoderamiento (empowerment) en destino. Este tipo de organizaciones aumentó en número cuando el consulado mexicano en Los Ángeles comenzó a patrocinar su desarrollo. "De acuerdo con 
Zabin y Escala (1998), más de 170 asociaciones de oriundos de 18 estados mexicanos estaban activas en 1998 en el área de Los Ángeles, muchas se clasificaban en el rango de grupos sin ánimo de lucro" (Goldring: 2002a, 63). La mayoría de éstas se organizaba de acuerdo con el origen de sus miembros, ya sea a nivel local o regional, y se unía para hacer sus demandas al Estado mexicano. De esta manera, aunque no estuvieran físicamente en territorio, no dejaban de ser ciudadanos mexicanos con derechos. Este tipo de organizaciones no fue el único medio que encontraron los mexicanos de primera generación para relacionarse tanto con la comunidad de origen como con la de destino. Al mismo tiempo se constituyeron comunidades religiosas, deportivas y también asociaciones voluntarias enfocadas a dar sentido a sus vidas en Estados Unidos.

Por su parte, el Estado mexicano no se interesó por ellas hasta 1980, cuando una serie de nuevas políticas y programas marcaron un cambio en la política nacional frente a los emigrantes en Estados Unidos. Este nuevo interés tenía, en principio, tintes políticos, debido al apoyo que los migrantes le estaban brindando a Cuauhtémoc Cárdenas -candidato de la oposición del entonces gobierno del PRIpara las elecciones de 1988. Por esta razón, el Partido Revolucionario Institucional (PRI) decidió estrechar los lazos con la diáspora mexicana. Otro factor importante fue la regularización de tres millones de mexicanos en 1986, quienes a pesar de ser ciudadanos estadounidenses, continuaban teniendo lazos fuertes con México. Un tercer factor fue la posibilidad de firmar un Tratado de Libre Comercio con el país vecino, que propiciaba la participación de mexicanos en ambos lados de la frontera. Finalmente, se buscaba que los mexicanos continuaran enviando remesas al país y que éstas pudieran ser utilizadas para proyectos productivos (Ibid: 2002a). Estas nuevas estrategias florecieron en los 90, durante el gobierno de Carlos Salinas, quien inició programas para la promoción de actividades culturales, sociales y económicas con distintas comunidades migrantes en Estados Unidos y sus zonas de origen. Asimismo, facilitó la entrada y salida de mexicanos que viajaban periódicamente a México. En ese momento surge el programa Paisano, que estaba enfocado a la mejor del trato de la policía y los agentes migratorios hacia los mexicanos retornados o de visita. Pero quizá el programa más relevante, al menos para este tema, es Solidaridad, que ofrecía dos dólares (uno por parte del gobierno local y otro del gobierno federal) por cada dólar invertido en México por los 
migrantes. Aunque el programa no tuvo una duración muy larga, pues se quedó sin presupuesto al terminar Salinas su mandato, aún se mantiene vivo al menos en el estado de Zacatecas ${ }^{11}$. Los migrantes zacatecanos en Estados Unidos hicieron negociaciones por medio de la Federación de Clubes Zacatecanos en el Sur de California para continuar con esta labor ${ }^{12}$. "A través del programa Dos por Uno y los programas antes mencionados, el Estado mexicano construyó un sentimiento nacionalista y de lealtad en los paisanos, y usó sus deseos por ayudar a sus comunidades de origen para convertirse en socio de este proceso" (Ibid. 68).

Al observar las razones por las cuales los migrantes oriundos de una región se organizan en clubes, se puede ver que han "[...] sido marginados en varios casos de la corriente dominante cultural de la sociedad anglosajona estadounidense. En respuesta a la exclusión y tratando de buscar respeto social, estos migrantes han buscado una membresía y pertenencia alternativas en sociedades que no siempre los han proveído con las herramientas necesarias para obtener movilidad social y estatus" (Bada, 2004: 88). Más aún, se les hace responsables del desarrollo regional del país, en este caso México. Además se les pide que vayan más allá de inversión en infraestructura, buscando la financiación de proyectos productivos que generen empleo. Mientras el gobierno no garantice el acceso a servicios sociales, culturales, salud, educación, etc., no se podrán realizar inversiones en proyectos productivos, pues para los migrantes la prioridad está en la mejora de la calidad de vida de sus familias y amigos.

El 49.8\% de los migrantes michoacanos trabajan en el sector agrícola antes de ser parte del flujo migratorio, por lo cual es importante destacar que aún no se han logrado consolidar proyectos productivos agropecuarios de granos básicos, a pesar de que existe interés, por parte de varios clubes, de promocionar el rescate al campo abatiendo la usura de los acaparadores y aumentando los subsidios que se otorgan a pequeños productores para la adquisición de mejores semillas" (Bada, 2004: 89).

\footnotetext{
11 El predecesor de esta iniciativa es el Programa para las Comunidades Mexicanas en el Extranjero (PCME), que tenía por objeto estrechar lazos entre las personas de origen mexicano que vivían en Estados Unidos con este país, mediante programas de intercambio, tanto de estudio como de trabajo. A esto le siguió el establecimiento, en 2000, de una Oficina de Atención a Migrantes en el Extranjero que garantizaba la atención de migrantes más allá de las fronteras.

12 Es importante recordar que el programa nació de la nada y fue gracias a las negociaciones que hicieron los migrantes a lo largo del tiempo, hasta llamar la atención del gobierno mexicano e invitarlo a involucrase. Primero tímidamente (con el programa Uno por Uno) hasta llegar a vincular a otros rangos de poder. Fueron los zacatecanos los que iniciaron estas negociaciones hasta llegar ahora al programa Cuatro por Uno, que vincula además de al gobierno federal, regional, local, también a la empresa de envío de remesas más importante a nivel internacional, Money Gram.
} 
La actitud del Estado mexicano, al delegar el desarrollo en manos de los migrantes, denota que estamos ante una reorganización estatal que busca liberarse al menos parcialmente de las responsabilidades heredadas de la revolución, la cual hizo responsable al Estado del bienestar social, político y económico de sus habitantes. Los migrantes han respondido positivamente a este reto, pues se han organizado alrededor del supuesto que el Estado no puede garantizar absolutamente todo, y por ello han buscado su intervención cívica para cubrir algunas responsabilidades que éste ha descuidado. Sin embargo, en alguna medida creen que pueden ejercer cierta presión para que el Estado asuma algunas responsabilidades mínimas al menos a nivel de desarrollo y bienestar económico.

Los clubes de michoacanos también han logrado, como los zacatecanos y guerrerenses, instaurar el programa $3 \times 1$, que compromete al gobierno federal, estatal y local a contribuir con la misma cantidad enviada por los migrantes para proyectos de desarrollo. Para validar los proyectos ante la Secretaría de Desarrollo Social (SEDESOL), se enfrentaban a la poca cooperación de los municipios, ya que éstos tenían un presupuesto asignado para proyectos y no tenían interés en complicarse con iniciativas migrantes. Además, como los migrantes no representaban un colectivo electoral, no había necesidad de responder a sus demandas. Aunado a esto, el gobierno federal (SEDESOL) decidió recortar el presupuesto para estos proyectos, lo que generó el entorpecimiento en las comunicaciones entre clubes y gobierno federal. A fines de 2001 la SEDESOL tenía una oficina en Washington que ya había logrado iniciar contacto con estos clubes, sin embargo fue cerrada para 2003, truncando esta labor. A pesar de ello, el trabajo de los migrantes en beneficio del desarrollo local no se ha detenido, aunque no mediante proyectos productivos que generen empleo. Uno de los miembros de estos clubes (Club Ciudad Hidalgo) afirma en entrevista que prefieren continuar con donaciones filantrópicas que vayan más al desarrollo social de las comunidades, pues al participar en proyectos productivos podrían generarse envidias y malos entendidos. Si uno de los participantes de estos proyectos parece que tiene materialmente más que otro, esto podría generar problemas no sólo dentro del club, sino en la comunidad de origen. Además se tiene una gran desconfianza en el gobierno (federal), por lo que no podrían integrarlo en estas inversiones. Sin embargo, los zacatecanos han observado que es necesario hacer proyectos 
productivos, pues sólo con estos se puede dar vida a las comunidades en una perspectiva perdurable de mediano y largo plazo.

\begin{abstract}
Esta iniciativa es interesante en la medida que, de alcanzar a madurar, se sustentaría en una política pública orientada intencionalmente a retener los flujos migratorios en las comunidades de origen; sin embargo, esta situación también evidencia el problema de las contrapartes locales, pues si se trata de comunidades abandonadas no se sabría quiénes podrían encargarse del desarrollo de estos proyectos y de su seguimiento cercano, es decir, se realza el problema de las contrapartes en las comunidades de origen (González y Rivera: 2004, 16).
\end{abstract}

Esta situación no es la misma en los estados del centro, México y Puebla, sin embargo éstos necesitan mayor desarrollo de sus infraestructuras para poder pensar en proyectos productivos.

En cuanto a la autorización que debe dar la SEDESOL a iniciativas migrantes, ésta no necesariamente responde a sus exigencias. Es decir, está más favor de proyectos productivos que de desarrollo sociocultural, como se mencionó antes. Por ejemplo, fue promovida una iniciativa para financiar nuevos toriles, con el argumento de que los niños de la comunidad se estaban olvidando de las tradicionales charreadas. La SEDESOL se negó a incentivar este proyecto, pues afirmaba que no generaba ni desarrollo y mucho menos empleos a largo plazo.

\begin{abstract}
Lo mismo pasa con la construcción de escuelas y hospitales, dado que estos proyectos no son autofinanciables y el gobierno no puede hacerse responsable del salario de los maestros y los doctores, ni del mantenimiento en el largo plazo. [...] La agenda estatal para el desarrollo debe tener el rostro de un proyecto modernizador, que privilegia proyectos autofinanciables y autosustentables, sin importar el significado de los procesos culturales o las tradiciones y valores que son importantes para las comunidades que se pretenden desarrollar (Bada, 2004: 96).
\end{abstract}

Todo ello denota la importancia que tiene la participación de los migrantes en el diseño de programas que no respondan a necesidades generales. Es necesario mirar "[...] el punto de engarce de la política pública, es decir, en el momento donde se encuentran y conectan las intencionalidades de los programas gubernamentales y las de los migrantes y sus familias" (González y Rivera, 2004: 11). En este sentido, la comunidad zacatecana ha seguido de cerca el planteamiento de los programas, pues siendo una de las comunidades con mayor tradición migratoria, ha sido pionera también en las demandas sociopolíticas al gobierno mexicano.

El relativo éxito que presentan estas experiencias en el estado de Zacatecas, nos hace pensar que las propias formas de organización (en clubes de oriundos), el significado y el 
sentido asignado a sus localidades de origen y su relación con ellas, la dinámica de los desplazamientos de los inmigrantes zacatecanos, así como el hecho de que el programa 3×1 resultaba y había nacido precisamente de una iniciativa de los propios migrantes, se adecuaban perfectamente a las exigencias del diseño del programa (González y Rivera, 2004: 11).

\section{A manera de conclusión}

Las comunidades transnacionales mexicanas han tenido la iniciativa para la realización de proyectos sociales, e incluso ahora para avanzar en la formulación y desarrollo de proyectos productivos. Después de un largo recorrido migratorio, en el que primero se han establecido de manera regular en Estados Unidos, han comenzado a organizarse para brindar ayuda a sus comunidades de origen. Si bien en inicio se estructuraron como un medio para enfrentarse a la sociedad de destino, después de formar parte de ella, esas comunidades comenzaron a dirigir sus miradas al origen. Las redes sociales de los migrantes desempeñaron un rol destacado a la hora del establecimiento y/o interacción en la sociedad de destino. "[...] ya que responden a necesidades apremiantes y llenan vacíos que las relaciones políticas y económicas no pueden llenar o lo hacen parcialmente" (Moctezuma Longoria, 2003: 4). Estas redes facilitaron el intercambio y ayuda mutua entre los colectivos migrantes y sus familias. Estaban formadas en base a coincidencias, no sólo étnicas, sino también culturales. Por esta razón, se formaron comunidades de migrantes que provienen de una misma comunidad, que mantiene lazos en origen mediante prácticas transnacionales. Es decir, los migrantes viven en espacios distintos, dentro de los cuales van y vienen, y con ellos se forman nuevas experiencias sociales y culturales, y/o se combinan las conocidas.

Esto es, en los migrantes, las comunidades de origen y de destino mantienen entre Estados Unidos y México una identidad porosa, en la que, a un mismo tiempo y en espacios distintos sobrevive el pasado y el presente, lo tradicional y lo moderno, lo rural y lo urbano, lo campesino y lo proletario, envolviendo en un todo único las distintas prácticas y percepciones que aparentemente son contradictorias por no evolucionar de acuerdo a la lógica de la modernidad (Moctezuma Longoria, 2003: 8).

En la actualidad, las comunidades migrantes han comenzado a cruzar información con organizaciones formadas por colectivos distintos, lo que ha permitido diversificar sus acciones y negociaciones. En este sentido, se ha resaltado la importancia de la participación gubernamental en la construcción de proyectos de 
desarrollo, pero como un miembro más de un engranaje que va más allá de intereses políticos, pues está centrado en la comunidad. Los migrantes zacatecanos son un ejemplo de este equilibrio, ya que no han perdido terreno frente al gobierno, sino que han aprovechado la fuerza que tienen para negociar de igual a igual con éste. Los proyectos que se llevan a cabo en Zacatecas nacen de las necesidades de la población, los clubes de migrantes son los portavoces de estas demandas. Junto con el gobierno mexicano han comenzado a dar respuesta a las mismas.

En este sentido, en España falta mucho por hacer, pues las asociaciones no tienen todavía una influencia real sobre ninguna decisión gubernamental. Quizá esto se deba a lo novedoso del fenómeno y, por tanto, se podría esperar que con el tiempo las organizaciones migrantes participaran de manera más activa en el destino de sus países de origen. Lo que hay que recordar es que estas agrupaciones deben responder únicamente a los intereses de sus agremiados, sin importar si estos van en detrimento del poder estatal. Mientras los migrantes mantengan el control de los futuros proyectos de desarrollo, habrá cierta garantía de satisfacción comunitaria, ya que el gobierno, en general, se deja llevar por intereses políticos que entorpecen la labor primordial. Por esta razón, es importante que sean las asociaciones de migrantes, con apoyo de las asociaciones en origen, quienes identifiquen las necesidades a cubrir y financien proyectos de desarrollo. Sin importar si son de carácter productivo o social. Un punto a destacar es que los proyectos que ya están financiando las asociaciones mexicanas en Estados Unidos no dependen de las transferencias financieras, sino de las cuotas de membresía. Plantear proyectos de desarrollo que vinculen a los migrantes y sus remesas puede resultar erróneo. Como hemos observado a lo largo del trabajo, estas transferencias son privadas y utilizadas generalmente para la manutención de la familia en origen. El éxito de los proyectos surgidos de las asociaciones mexicanas tiene relación con la autonomía obtenida al contar con un presupuesto específico para proyectos de desarrollo, y por supuesto con el lugar que se han ido ganando a lo largo de los años frente al gobierno mexicano y los propios migrantes. La confianza es primordial para la vinculación de los migrantes en iniciativas de desarrollo, por ello el gobierno debe mantenerse como un actor más y no como el propulsor de dichas iniciativas. 


\section{Referencias}

Bada, X. (2004). "Clubes de michoacanos oriundos: desarrollo y membresía". Migración y Desarrollo.

Goldring, Luin (1999). "El Estado mexicano y las organizaciones transmigrantes: ¿reconfigurando la nación y las relaciones entre Estado y sociedad civil?" En Fronteras Fragmentadas. Gail Mummert Ed. Colegio de Michoacán: México.

Goldring, Luin (2002). "Remesas familiares, remesas colectivas y desarrollo: implicaciones sociales y políticas de una desagregación de remesas". York University.

Goldring, Luin (2002a). "The mexican state and trasnmigrant organizations: Negotiating the boundaries of membership and participation". Latin American Research Review, 37(3).

González Ortiz, F. y Rivera, L. (2004). Migrantes y políticas públicas. Apuntes desde la experiencia del programa 'Iniciativa Ciudadana Tres por Uno' en los estados de México y Puebla. El Colegio Mexiquense y CIESAS: México.

Guarnizo, L. E. y Smith, M. P. (1999). "Las localizaciones del transnacionalismo". En Fronteras Fragmentadas. Gail Mummert Ed. Colegio de Michoacán: México.

Moctezuma, M. (2003). "Territorialidad socio-cultural y política de los clubes zacatecanos en Estados Unidos". Primer Coloquio Internacional de Migración y Desarrollo: Transnacionalismo y nuevas perspectivas de integración. Zacatecas: México.

Moraes, Natalia. (2004). "Entre el transnacionalismo y la relocalización: un estudio del movimiento asociativo de los migrantes uruguayos en España". Laboratorio de Estudios Interculturales de la Universidad de Granada.

Naïr, Sami (1997), Rapport de bilan et d'orientation sur la politique de codeveloppement lieé aux flux migratoires, París.

OCDE, El porvenir de las migraciones, París, 1987

Terrón, Anna (2001). "El debate sobre la inmigración en la Unión Europea". Revista CIDOB d'affers internacionals $\mathrm{n}^{\circ} 53$, Barcelona.

Terrón, Anna (2004). Migraciones y relaciones con países terceros, Documentos CIDOB, Barcelona.

Smith, M. P. y Guarnizo, L. E. (2002). Transnationalism from below. Comparative Urban and Community Research, vol. 6. Transaction Publishers: New Brunswick (U.S.A) and London (U.K).

Zúñiga, N. (2005). La migración: un camino entre el desarrollo y la cooperación, Centro de Investigación para la Paz (CIP-FUHEM): Madrid. 